\title{
The Steel Bicycle Project: Bringing Together Tube Manufacturers, Frame Builders, and Engineers through Sports Engineering ${ }^{\dagger}$
}

\author{
Derek Covill 1,*, Jean-Marc Drouet ${ }^{2}$ and Andrés Arregui Velázquez ${ }^{3}$ \\ 1 School of Computing, Engineering and Mathematics, University of Brighton, Cockcroft Building, \\ Lewes Road, Brighton BN2 4GJ, UK \\ 2 VÉLUS Laboratory, Mechanical Engineering Department, Université de Sherbrooke, \\ 2500 Boulevard de l'Université, Sherbrooke, QC J1K 2R1, Canada; jean-marc.drouet@usherbrooke.ca \\ 3 Escuela Técnica de la Bicicleta, 28019 Madrid, Spain; av@arreguivelazquez.com \\ * Correspondence: d.covill@brighton.ac.uk; Tel.: +44-(0)1273-64-2331 \\ + Presented at the 13th conference of the International Sports Engineering Association, Online, \\ 22-26 June 2020.
}

Published: 15 June 2020

\begin{abstract}
Steel, being the most commonly used bicycle frame material, has a major role to play in future developments within the bicycle industry, and there is scope to enhance the role of engineering in the development of steel bicycles. This paper introduces The Steel Bicycle Project (TSBP), an open-ended project which aims to raise awareness of engineering principles that relate to steel bicycle frames and aims to support frame builders in designing and fabricating better and safer products. In this paper, we give details of the main project themes (Design and simulation, Materials and fabrication, Testing and measurements, Knowledge and education) and outcomes. We also present some initial activities from the early stages of the project and will discuss general models to bring together key partners under the umbrella of the sports engineering community.
\end{abstract}

Keywords: The Steel Bicycle Project; TSBP; sports engineering; bicycle engineering; frame building

\section{Introduction and Project Rationale}

Steel bicycle frame building dates back to the 19th century, and for much of the time since, the primary method for joining tubes together to make bicycle frames has been to braze them into pressed or cast lugs or using fillets. Ever since, material properties have continually improved, allowing for thinner, lighter tubes to be used, and new fabrication techniques have been introduced (e.g., TIG welding). However, the development and fabrication of steel bicycle frames remains as much rooted in craftsmanship, art, and marketing as technical considerations. Steel, being the most commonly used bicycle frame material, has a major role to play in future developments within the bicycle industry, and there is scope to enhance the role of engineering in the development of steel bicycles. For instance, from the authors' perspective, the following are key considerations moving forward:

- There is a unique opportunity to improve products by bringing resources and expertise together that may not cross paths otherwise (i.e., frame builders and engineers);

- Frame builders are looking at new ways to address sustainability issues and to encompass the whole product life cycle [1] and sustainability [2];

- Engineers are good at analysing (e.g., doing calculations, developing finite element analysis (FEA) models) but may not have fabricating skills;

- Bicycle frame builders are good at fabricating but may not have access to engineering expertise;

- There are potential communication issues between engineers and non-engineers; 
- There is a need to carry out an assessment of the needs of frame builders;

- A review of literature revealed that there is still work to be done to fully understand the key elements regarding steel bicycle frames design, fabrication, and behaviour (in both static and fatigue) [3];

- There is scope to bring more science and engineering research into frame building, for example, in improving frame specification, drawings and design processes, improving the repeatability of fabrication techniques and the utilisation of testing and experimentation (beyond the research done by tube manufacturers to, for example, improve weldability, optimise the cross-sectional area or butting profiles of tubes).

In an attempt to take a step forward to enhance the role of engineering in the development of steel bicycles, we introduce here The Steel Bicycle Project (TSBP), an open-ended project which aims to raise awareness of engineering principles that relate to steel bicycle frames and to support frame builders in designing and fabricating better and safer products. At the heart of TSBP is the tenet to bring together the following key partners: (1) tube manufacturers who specialise in the development and production of tubing materials, tube sets, and their associated fabrication processes (e.g., the specification of brazing rods or welding techniques); (2) frame builders who have expertise in fitting the bicycle to the rider, frame design, and fabrication processes; (3) engineers (practicing, academic, and students) with relevant expertise in, for example, mechanical, structural, materials, manufacturing, and design aspects. We strongly believe that collaboration between these partners is essential in order to realise the many potential mutual benefits for frame builders and engineers, which will ultimately benefit end users. We hope this project will serve as a model for the sports engineering community, providing a means of bringing together industry professionals, academics, and students.

In this paper, we give details of the main project themes and outcomes and also present some initial activities from the early stages of the project and will discuss general models to bring together the aforementioned key partners under the umbrella of the sports engineering community.

\section{Project Themes}

The project has been structured into four main themes: (1) Design and simulation; (2) Materials and fabrication; (3) Testing and measurements; (4) Knowledge and education. These themes are shown in Figure 1 and are outlined in more detail with some examples of preliminary work in the following sections.

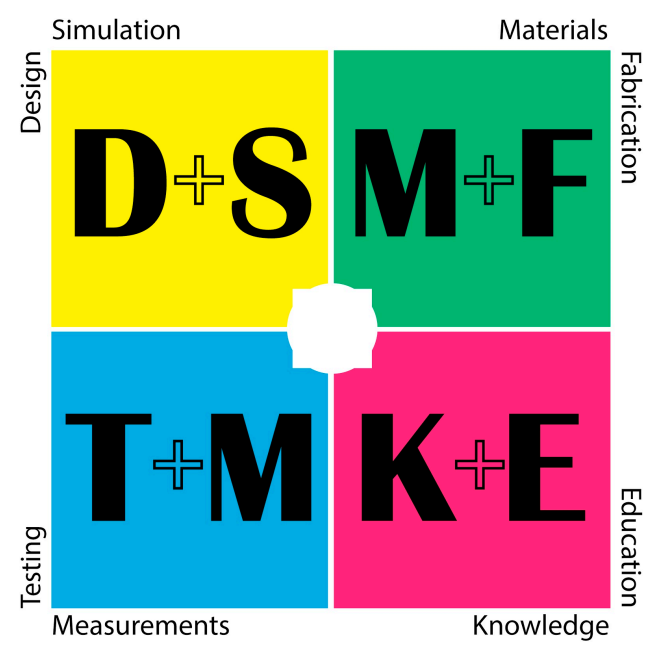

Figure 1. The four main themes of The Steel Bicycle Project (TSBP): (1) Design and simulation; (2) Materials and fabrication; (3) Testing and measurement; (4) Knowledge and education. 


\subsection{Design and Simulation}

This theme focuses on the aspects of good practice with regard to engineering design and how these might relate to the process of designing new bicycles. For instance, some aspects to consider are the use of design specifications, engineering drawings, and more generally, understanding how the relevant design attributes of a bicycle influence its performance. Computer simulations have been used since the 1980s [3-6] (Figure 2) and can be used to complement experimental testing to gain a fuller understanding of bicycle behaviour. Previously published work in this area has aimed to help understand how specific frames might behave under known load conditions [3-6], how the frame geometry (in the form of tube lengths and angles, and tube section profiles) can influence the stiffness of the frame or parts of the frame [3,7-9], and how optimisation techniques can be used on frame geometry $[7,10]$. One aim in this theme is to help frame builders assess how design changes can affect the mechanical behaviour of their frame designs relative to benchmark designs, but also, in absolute terms, by validating model outputs using experimentation. Establishing collaborations with tube manufacturers will help to ensure that data is complete and accurate in terms of mechanical properties and tube geometry in order to generate quality computer-aided design (CAD) and mesh data.

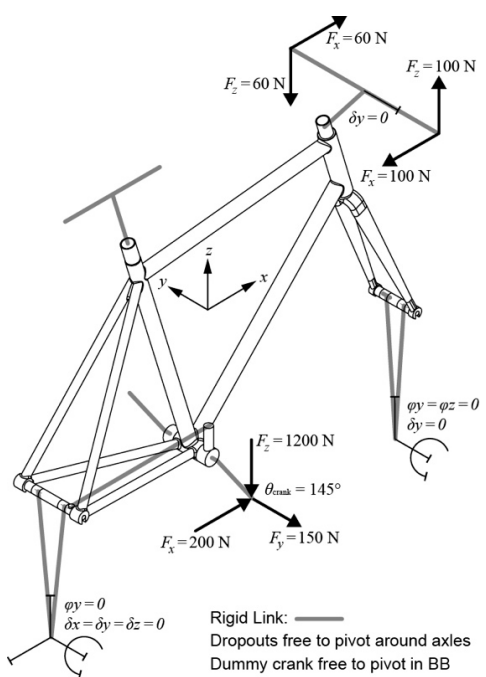

(a)

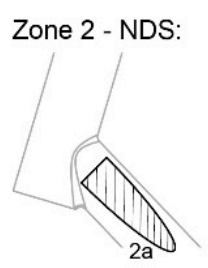

Zone 4:

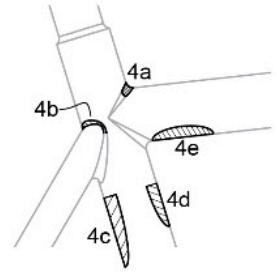

(b)

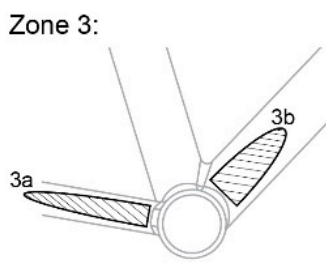

Zone 5:

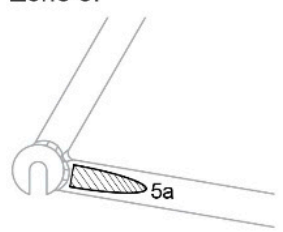

Figure 2. A recent example of modelling and simulation on steel bicycle frames: (a) FEA has been applied to bicycle frames with load cases based on field measurements [3]; (b) Areas of high stress for specific load cases can be identified and evaluated [3].

\subsection{Materials and Fabrication}

The properties of materials used in bicycle frame construction influence how bicycles perform structurally, and the fabrication techniques used to shape and join these materials can significantly alter these properties. While the body of knowledge relating to metallurgy and the properties of joining methods is well established in engineering, there is much work to be done to make this information accessible and relevant to frame builders, but also to help understand the strength behaviour (both static and fatigue) of bicycles specifically. For instance, key considerations may include developing an understanding of factors affecting the heat-affected zone (HAZ) and how this may vary with fabricator, technique, or conditions (e.g., when welding dissimilar steels or when joining air hardening steels) and could provide a good deal of insight for the industry and for tube manufacturers. In fact, insights into important research areas can be shared by tube manufacturers who have direct knowledge of the issues, concerns, and needs of frame builders who use their tubes. Engineers may have access to equipment, testing facilities, or scientific capabilities that tube manufacturers may not possess and so, by sharing knowledge, all parties can benefit. Figure 3a shows some initial work that has been carried out by the authors after discussions with tube manufacturers 
to understand the bimetallic bonds for commonly used frame building materials (in this case steel and brass Cu60\%, Zn38\%) using scanning electron microscopy (SEM). Other brazing compounds have also been tested and the intention is to analyse this for a number of frame builders to help determine an appropriate minimum fillet size, among other things. Figure $3 \mathrm{~b}$ shows a test to determine the hardness in the heat-affected zone as a function from the filler material, a fillet-brazed joint (in this case a brass filler) with a range of filler materials tested.

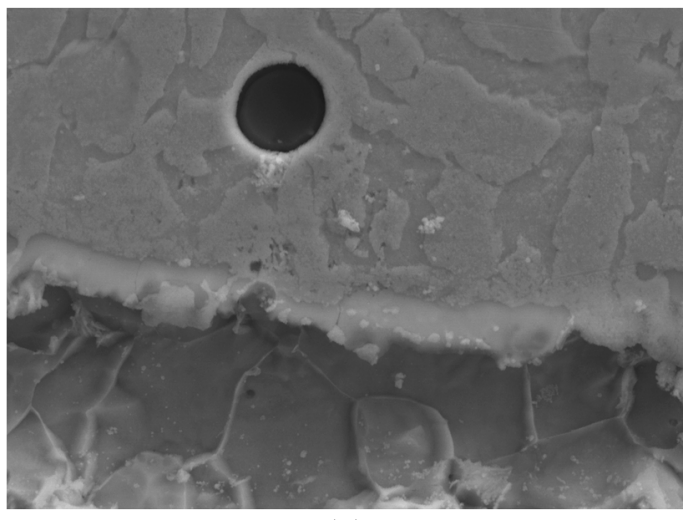

(a)

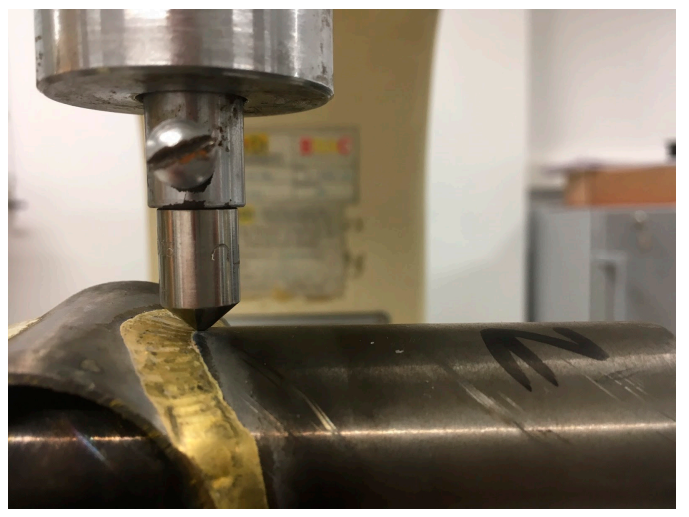

(b)

Figure 3. (a) Scanning electron microscopy (SEM) at the bimetallic bond between steel and brass (Cu60\%, Zn38\%). The strength of this interaction (i.e., the chemical compatibility) will determine the strength of the joint and the minimum fillet size; (b) Tests to determine the hardness in the heataffected zone (HAZ).

\subsection{Testing and Measurements}

Developing experimental test rigs and carrying out scientific measurements can help the development of knowledge and help with the design and testing phases to understand how the bicycle frames behave and how this can be influenced by design and fabrication approaches. Clearly, there is a need to address the requirements of official standards in the first instance (e.g., BS EN ISO 4210-Cycles: Safety requirements for bicycles [11]). However, there are some good examples of bicycle test rig or transducer development projects in the literature which go further than these standards which have, for example, helped to understand how numerical simulations can be used to develop strain gauge transducers for dynamic measurements [12] or describe the test rig development process for measuring bicycle frame stiffness [13]. Generally, though, these projects have not yet been developed with the intention to make them fully open-access, as has been the case in other industries such as furniture design and fabrication [14] and more generally in machine design [15]. Tube manufacturers, again, have a key role to play here since testing data can be directly related to the performance of their products and can help them understand how to improve fabrication techniques, and more generally bicycle frame behaviour, through collaboration with engineers and frame builders. The authors have developed a prototype test rig (Figure 4) that will allow for welded and brazed bicycle frame joints to be tested for their static and fatigue strengths in isolation under bending loads. This has included the design of a set of customised expanding arbors to fix and apply loads to tubes, and loads can be applied using hung masses or using a stepper motor or using a pneumatic cylinder with vertical displacement and vertical forces logged on a PC or customised datalogger. Pneumatic and more advanced control capabilities for fatigue testing in bending are currently being developed with future projects to focus on torsion loading. The intention is for these and other test rigs to be developed as open-access projects with all CAD files, drawings, electronics, assembly plans, and test plans made freely available on an open-access website, with further sharing of resources to enable more access to engineering measurements and testing capabilities for frame builders and research. 


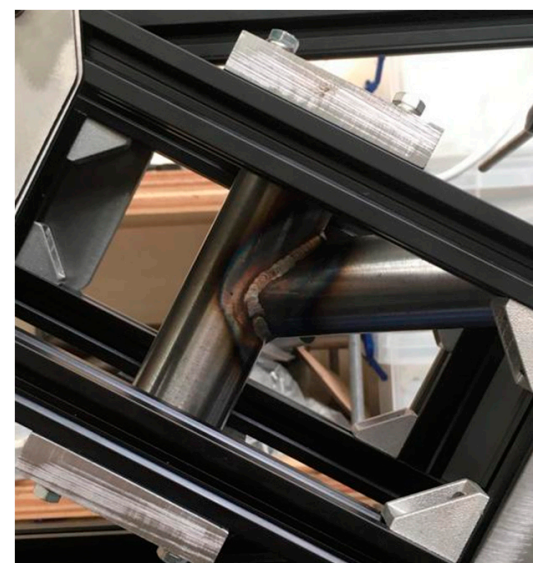

(a)

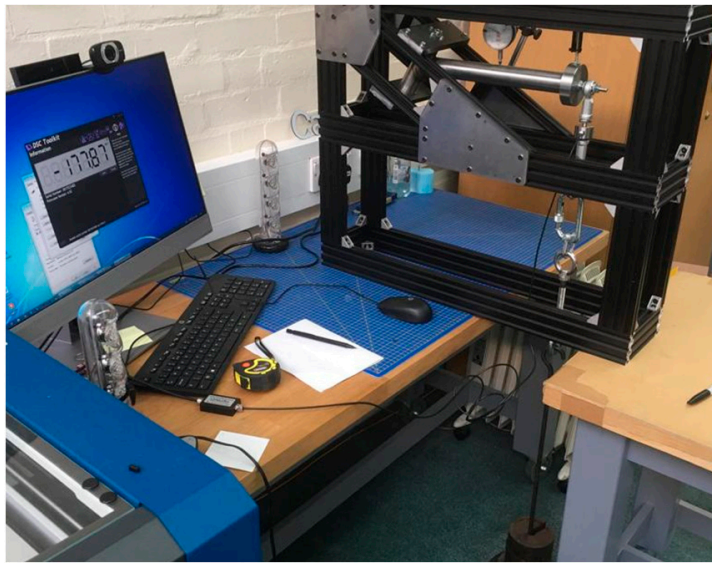

(b)

Figure 4. The authors have developed a prototype test rig that will allow for welded and brazed bicycle frame joints to be tested for their static and fatigue strengths: (a) the method of fixation using a set of customised expanding arbors; (b) loads can be applied using hung masses or stepper motor or pneumatic cylinder.

\subsection{Knowledge and Education}

There is a need for engineers to develop ongoing relationships with frame builders and to identify collective needs with the help of tube manufacturers who already work closely with frame builders. Useful outcomes and resources that arise from the projects that occur within these networks need to be communicated using appropriate media and in relevant literature in a way that is accessible for all in the public domain (i.e., not private consultancy or research that is kept a secret). The aim here should be to publish findings of evidence-based research, which may also include guidelines based on robust data and the debunking of some commonly held myths. The authors have started to gather data from surveys and semi-structured interviews to help gauge the appetite (of frame builders, tube manufacturers, and end users) for this project and to help identify the collective needs of the frame builders. We have also started to focus our attention on creating a public presence at high-profile events, such as Bespoked Bristol (UK) and the British Science Festival, in order to communicate research outcomes and start to build relationships with frame builders and industry.

\section{Project Outcomes}

Currently, TSBP is an open-ended, long-term initiative, with no explicitly defined end point. However, we have produced a list of intended outcomes from the project; these outcomes are not fixed or exhaustive, and we welcome the contribution and collaboration of others in this endeavour. As such, here is a list of possible outcomes for TSBP:

- $\quad$ Basic principles of bicycle-related engineering design and structural analysis explained, and useful calculators and other tools developed (e.g. software);

- A comprehensive database or repository of useful knowledge and data for bicycle designers and frame builders, including CAD/FEA models and analysis guidelines or demonstrations (e.g., how to apply loads/boundary conditions);

- A series of case studies of best practices in the industry relating to engineering rigour;

- A set of bicycle frame design guidelines based on evidence from engineering research;

- The development of do-it-yourself (DIY) open-access test benches (e.g., for static and fatigue testing) and a standardised method for joint testing;

- A clear understanding of frame failure modes and guidance on approaches to risk assessment and management as they relate to, for example, load capacity, maintenance, low temp ductile to brittle transition;

- The publication of open-access research papers that are useful and relevant for researchers, bicycle designers, and frame builders; 
- A series of online courses, testing kits or self-assessment exercises that are useful and relevant for researchers, bicycle designers, and frame builders;

- A means to foster collaboration and develop a community of practice;

- A culture that welcomes the involvement of students on projects that relate to all aspects of TSBP;

- A collaboration model for the sports engineering community;

- A culture of striving for better and safer products that will directly benefit end users.

\section{Conclusions}

The Steel Bicycle Project (TSBP) is a long-term initiative which brings together tube manufacturers, frame builders, engineers, and end users in a collaboration that strives to be a model of collaboration and good practice for the sports engineering community. The project has been structured into four main themes relating to steel bicycles: (1) Design and simulation; (2) Materials and fabrication; (3) Testing and measurements; (4) Knowledge and education. Some progress has been made by the authors in all of these areas; however, we welcome the contribution and collaboration of others in this endeavour. We have produced a list of possible outcomes that have the potential to enhance the role of engineering and raise awareness of engineering principles that relate to steel bicycle frames in order to support frame builders in designing and fabricating better and safer bicycles.

\section{References}

1. Imagine Project. Available online: https://www.islabikes.co.uk/imagine-project/ (accessed on 10 October 2019).

2. Subic, A.; Mouritz, A.; Troynikov, O. Sustainable design and environmental impact of materials in sports products. Sports Technol. 2009, 2, 67-79. doi:10.1080/19346182.2009.9648504.

3. Covill, D.; Allard, P.; Drouet, J.-M.; Emerson, N. An assessment of bicycle frame behaviour under various load conditions using numerical simulations. Procedia Eng. 2016, 147, 65-670.

4. Soden, P.; Millar, M.; Adefeya, B.; Wong, Y. Loads, stresses and deflections in bicycle frames. J. Strain Anal. 1986, 21, 185-195.

5. Peterson, L.; Londry, K. A New Tool for Bicycle Frame Design: The Strain Energy Design Method. Bike Tech: Bicycling Magazine's Newsletter for the Technical Enthusiast. Summer 1986; Volume 5. Available online: https://www.sheldonbrown.com/rinard/fea.htm (accessed on 19 May 2020).

6. Hull, M.; Bolourchi, F. Contributions of rider-induced loads to bicycle frame stress. J. Strain Anal. 1988, 23, 105-114.

7. Covill, D.; Begg, S.; Elton, E.; Milne, M.; Morris, M.; Katz, T. Parametric finite element analysis of bicycle frame geometries. Procedia Eng. 2014, 72, 441-446.

8. Covill, D.; Blayden, A.; Coren, D.; Begg, S. Parametric finite element analysis of steel bicycle frames: The influence of tube selection on frame stiffness. Procedia Eng. 2015, 112, 34-39.

9. Covill, D.; Drouet J.-M. On the effects of tube butting on the structural performance of steel bicycle frames. Proceedings 2018, 2, 216. doi:10.3390/proceedings2060216.

10. Maestrelli, L.; Falsini, A. Bicycle frame optimization by means of an advanced gradient method algorithm. In Proceedings of the 2nd European HTC, Strasbourg, France, 30 September-1 October 2008.

11. BS EN ISO 4210-Cycles. Safety Requirements for Bicycles. Available online: https://doi.org/10.3403/BSENISO4210 (accessed on 19 May 2020).

12. Drouet, J.-M.; Champoux, Y. Designing a Strain Gauge Transducer for Dynamic Load Measurement in Cycling Using Numerical Simulation. Procedia Eng. 2014, 72, 304-309.

13. Vanwalleghem, J.; De Baere, I.; Loccufier, M.; Van Paepegem, W. Development of a test rig and a testing procedure for bicycle frame stiffness measurements. Sports Eng. 2018, 21, 75-84.

14. Open Source Ecology. Available online: https://www.opensourceecology.org (accessed 11 October 2019).

15. Open Desk. Available online: https://www.opendesk.cc (accessed on 11 November 2019).

(C) 2020 by the authors. Licensee MDPI, Basel, Switzerland. This article is an open access article distributed under the terms and conditions of the Creative Commons Attribution (CC BY) license (http://creativecommons.org/licenses/by/4.0/). 